\title{
The Mediating Role of Depressive Symptom Severity in the Relationship between Obsessive-Compulsive Disorder and Quality of Life
}

\author{
Soon Li Lee ${ }^{1}$, Cai Lian Tam ${ }^{1}$, Beng Kah Song ${ }^{2} \&$ Tina Ting Xiang Neik ${ }^{2,3}$ \\ ${ }^{1}$ Jeffrey Cheah School of Medicine and Health Sciences, Monash University, Malaysia \\ ${ }^{2}$ School of Science, Monash University, Malaysia \\ ${ }^{3}$ Faculty of Pharmacy, SEGi University Kota Damansara, Selangor, Malaysia \\ Correspondence: Cai Lian Tam, Jeffrey Cheah School of Medicine and Health Sciences, Monash University, \\ Malaysia. Tel: 60-3-5514-4974. E-mail: tam.cai.lian@monash.edu
}

Received: September 14, 2014 Accepted: October 10, 2014 Online Published: December 2, 2014

doi:10.5539/ass.v11n1p97

URL: http://dx.doi.org/10.5539/ass.v11n1p97

\begin{abstract}
The present study investigated the mediating role of depressive symptom severity in the relationship between OCD severity and quality of life (QoL) with Malaysian sample. A total of 126 Malaysians were required to complete the questionnaires given, which measure for different aspects of QoL, OCD and depression severity. The results revealed that depression severity and OCD severity were positively correlated. OCD severity was negatively correlated with physical functioning, emotional well-being, social functioning and general health. In addition, depression severity mediated the relationship between OCD severity and emotional well-being and social functioning.
\end{abstract}

Keywords: depressive symptom severity, obsessive-compulsive disorder, quality of life

\section{Introduction}

Obsessive-compulsive disorder (OCD) is a disorder characterized by the presence of intrusive thoughts or obsessions and repetitive behaviors such as physical or mental rituals (American Psychiatric Association, 2000). Studies have indicated that OCD is capable of causing profound disabilities in social and family relationship (Hollander, 1997; Koran et al., 1996; Stein et al., 1996), learning ability (Stein et al., 1996), and occupational functioning (Hollander, 1997; Koran et al., 1996; Stein et al., 1996; Leon, Portera, \& Weissman, 1995). OCD also increases the risk for other disorders such as depression (Koran et al., 1996). Comorbidity is common for patients with OCD since past studies had estimated that $70 \%$ of the patients displayed depressive symptoms as well as the other form of anxiety disorders (Rasmussen, 1994; Storch et al., 2010). Considering the impairments associated with OCD and the rate of comorbidity, it is not unusual that quality of life (QoL) would be affected as well. Based on the literature review, it was gathered that most of the scope in OCD prevalence study is presented as a comorbidity of other mental disorders. For example, in the national survey from the Australian population, $79.7 \%$ of OCD patients have at least one of the mental disorders, with major depression listed as the highest comorbidity disorder at 54\% (Crino, Slade, \& Andrews, 2005). In Malaysia, there is limited published data on OCD, though . most of them, if available, cover comorbidity (Hamid \& Razak, 2010; Jaafar, Midin, \& Reddy, 2009). As such, there is a demand for more OCD studies in Malaysia.

There are four domains of QoL, which include physical health, emotional well-being, social functioning and general health (Ware, Snow, Kosinski, \& Gandek, 1993). Past studies have established that OCD has the capability to impair QoL related aspects (Hou, Yen, Huang, Wang, \& Yeh, 2010; Blom, Hagestein-de Brujin, De Graaf, Ten Have, \& Denys, 2011; Srivastava, Bhatia, Thawani, \& Jhanjee, 2011; Subramaniam, Abidin, Vaingankar, \& Chong, 2012). The relationship between OCD and QoL, however, is not as simple as depicted by past studies. Hou et al. (2010) stated that the relationship between OCD and QoL aspects are influenced by multiple factors and one of them is the comorbid of depression. In addition, they stated that when depression comorbids with OCD, a more severe impairment will be inflicted on QoL. Cassin, Richter, Zhang, and Rector (2009) stated that with the comorbidity of depression, patients with OCD reported greater decrement in their QoL aspects. These outcomes have been consistently replicated by other studies (Abramowitz, Storch, Keeley, \& 
Cordell, 2007; Besiroglu, Uguz, Saglam, Agargun, \& Cilli, 2007). In fact, Kugler et al. (2013) have suggested depression as the mediator for the relationship between OCD and QoL. From their study, the depression severity significantly mediated the relationship for OCD severity across the domains of emotional well-being, social functioning and general health, but not physical functioning.. In this light, the present study aims to show that OCD severity may contribute to depression severity due to withdrawal from certain activities, and therefore, negatively impacted QoL.

To the author's knowledge, there is no published work on the impact of OCD on QoL with Malaysian sample. Given that depression, which is highly comorbid with OCD (Cassin et al., 2009; Hou et al., 2010), is a common psychiatric feature in Malaysia (Sherina, Rampal, \& Mustaqim, 2004; Sherina, Rampal, Aini, \& Norhidayati, 2005; Imran, Azidah, Asrenee, \& Rosediani, 2009), it is arguable that most Malaysians will display the symptoms of OCD. However, the prevalence rate of OCD in Malaysia is unknown due to limited data..

The aim of the present study is to investigate the mediating role of depressive symptom severity in the relationship between OCD severity and QoL in Malaysian population.Based on Kugler et al. (2013)'s work, we predict the same that OCD severity is expected to correlate with emotional well-being, social functioning and general health but not with physical functioning.

Following this, we have formulated two research questions as follow:

(1) Is OCD severity related to emotional well-being, social functioning, general health and physical functioning?

(2) Is there any mediating role of depression severity for the relationship between OCD severity and general health?

\section{Method}

\subsection{Participant (Subject) Characteristics}

A total of 126 university students were recruited from a university in Malaysia and the public settings. The age of the participants were in the range of 18 to 63 years old $(\mathrm{M}=28.90, \mathrm{SD}=10.21)$, with $23.8 \%$ male $(\mathrm{N}=30)$ and $76.2 \%$ female $(\mathrm{N}=96)$. The ethnic distribution was Chinese $(76.2 \%, \mathrm{~N}=96)$, Malay $(11.9 \%, \mathrm{~N}=15)$, Indian $(4.8 \%, \mathrm{~N}=6)$ and other $(7.1 \%, \mathrm{~N}=9)$.

\subsection{Sampling Procedures}

The study was advertised through flyers and posters. Interested participants were handed with a copy of the questionnaire. They were allowed to withdraw at any stage of the study. However, upon submission of the questionnaires, withdrawal is impossible since there was no identifier assigned to the questionnaires. Following Preacher and Hayes' (2004) recommendation, the Obsessive Compulsive Inventory-Revised (OCI-R) which measures for the predictor variable was placed ahead of the Patient Health Questionnaire-9 (PHQ-9), which measures for the mediator or depression severity. The RM36 which measures for the outcome variables was placed after these items. This will allow time for the predictor variable to exert influence on the mediator, and therefore, increase the validity for the present study.

\subsection{Measures and Covariates}

For current study, four scales were utilized. They were the Demographic Data Questionnaire, thePHQ-9, OCI-R, and the RAND MOS-36-item Short Form Health Survey (RM36).

The Demographic Data Questionnaire was used to collect general information from the participants, such as: age, gender, and ethnicity.

The PHQ-9 consists of nine items which measure depression severity (Kroenke, Spitzer, \& Williams, 2001). A sample item will be "How often during the past 2 weeks were you bothered by feeling down, depressed, or hopeless?" The Cronbach's alpha found with Malaysian sample was .70 (Sherina, Arroll, \& Goodyear-Smith, 2012). For the present sample, the Cronbach's alpha was .77, which is slightly higher than the value found from past study.

The OCI-R is a self-report questionnaire which measures for OCD severity with eighteen items (Foa et al., 2002). A sample item is "I check things more often than necessary." For the present study, the Cronbach's alpha was .93 .

The RM36 measures for QoL aspects (Ware \& Sherbourne, 1992). It consists of eight subscales, namely: physical functioning; physical role functioning; emotional role functioning; perceptions of general health; emotional health; vitality/energy; bodily pain; social functioning. A sample item will be "Compared to one year ago, how would you rate your health in general now?" These items were available to the public and can be 
retrieved on the RAND Corporation's (n.d.) website. For the present study, the subscales of physical health, emotional well-being, social functioning and general health were used. The Cronbach's alphas were .87, .86, .70, and .70 respectively.

\section{Results}

Initially, missing values were imputed with the hot deck imputation, which estimates missing values with categorical data (Myers, 2011). Estimation was based on participants' gender. The data cleaning proceeded with outliers screening, which revealed the presence of three univariate outliers. Analyses were conducted with and without the outlier. Since the outliers did not influence the statistical analyses, they were retained. The distributions for the variables were normally distributed. Furthermore, the basic assumptions for regression and mediation were met. The mean for each item was computed before summation for the composite scores. This procedure was applied on each scale. Table 1 consists of the means and standard deviations.

Table 1. Descriptive statistics of the different questionnaires used

\begin{tabular}{cc}
\hline Variables & $M(S D)$ \\
\hline PHQ-9 & $.78(.48)$ \\
OCI-R & $.98(.72)$ \\
Physical functioning & $83.96(16.74)$ \\
Emotional well-being & $53.69(13.95)$ \\
Social functioning & $71.72(24.35$ \\
\hline
\end{tabular}

Pearson's correlations revealed that both PHQ-9 and OCI-R were positively correlated $(r=6.52, p<.001)$. The OCI-R was negatively correlated with physical functioning $(r=-.40, p<.001)$, emotional well-being $(r=-.30, p$ $<.001)$, social functioning $(\mathrm{r}=-.45, \mathrm{p}<.001)$ and general health $(\mathrm{r}=-.28, \mathrm{p}<.001)$.

For the present mediation analysis, a macro provided by Preacher and Hayes (2004) was used. In short, this macro allows the estimation for: 1) the total effect from predictor variable on dependent variable (YX); 2) the direct effect of predictor variable on the mediator variable (MX); 3) the effect of mediator on the dependent variable, controlling for predictor variable (YM.X); 4) the direct effect of predictor variable on dependent variable, controlling for the mediator variable (YX.M); 5) the indirect effect of the predictor variable on dependent variable with bootstrapped estimates of $95 \%$ and $99 \%$ confidence interval. The bootstrapped estimate is significant if the lower bounds and upper bounds for $95 \%$ and $99 \%$ confidence intervals are greater than zero. The use of bootstrapped estimate to test the significance of the indirect effect superior to Sobel test as it can be used with small sample size with non-normal distribution properties. The bootstrapped ratio of 5000 bootstraps for indirect effect was used in present study. Therefore, for present study, mediation is assumed if 1) there is an effect to be mediated, and 2) the indirect effect is statistically significant in the direction predicted by mediation hypothesis.

The effect of OCD severity on physical functioning $(\beta=-9.40$, s. e. $=1.89, \mathrm{p}<.001)$ and depression severity $(\beta$ $=.43$, s. e. $=.04, \mathrm{p}<.001)$ were significant. Upon controlling for OCD severity, depression severity did not significantly predict for physical functioning $(\beta=6.42$, s. e. $=3.73, \mathrm{p}>.05)$. When depression severity was controlled, OCD severity still significantly predict for physical functioning $(\beta=-12.19$, s. e. $=2.48, p<.001)$. Bootstrapping confidence interval revealed that depression was not a significant mediator as the indirect effect was not significant $(2.79 ; 95 \%$ CI -1.39 to 5.81$)$.

The effect of OCD severity on general health was significant $(\beta=-7.64$, s. e. $=2.30, p>.01)$ and depression severity $(\beta=.43$, s. e. $=.04, \mathrm{p}<.001)$. Upon controlling for OCD severity, depression severity did not significantly predict for general health $(\beta=-8.57$, s. e. $=4.50, p>.05)$. When depression severity was controlled, OCD severity did not significantly predict for general health $(\beta=-3.91$, s. e. $=3.00, p>.05)$. Bootstrapping confidence interval revealed that depression was not a significant mediator as the indirect effect was not significant (-3.72; 95\% CI -8.14 to .67).

The effect of OCD severity on emotional well-being $(\beta=-5.78$, s. e. $=1.65, p<.01)$ and depression severity $(\beta$ $=.43$, s. e. $=.04, \mathrm{p}<.001$ ) were significant. Upon controlling for OCD severity, depression severity significantly predict for emotional well-being $(\beta=-13.87$, s. e. $=3.03, \mathrm{p}<.001)$. When depression severity was controlled, OCD severity did not significantly predict for emotional well-being $(\beta=.25$, s. e. $=2.02, p>.05)$. Bootstrapping confidence interval revealed that depression was a significant mediator as the indirect effect was significant $(-6.03 ; 95 \%$ CI -11.57 to -2.44$)$. 
The effect of OCD severity on social functioning $(\beta=-15.25$, s. e. $=2.69, p<.001)$ and depression severity $(\beta$ $=.43$, s. e. $=.04, \mathrm{p}<.001$ ) were significant. Upon controlling for OCD severity, depression severity significantly predict for social functioning $(\beta=-24.35$, s. e. $=4.88, \mathrm{p}<.001)$. When depression severity was controlled, OCD severity did not significantly predict for social functioning $(\beta=-4.66$, s. e. $=3.25, \mathrm{p}>.05)$. Bootstrapping confidence interval revealed that depression was a significant mediator as the indirect effect was significant (-10.58; $95 \%$ CI -15.45 to -6.32$)$.

As a precaution against bidirectionality of the mediation pathway, the domains of physical health, emotional well-being, social functioning and general health were entered as the predictor variables in four separate analyses, depressive symptom severity was entered as mediator and OCD severity was entered as the outcome variable. The obtained results were not significant, which suggests for the absence of bidirectionality.

\section{Discussion}

The present study investigates the mediating role for depressive symptom severity in the relationship between OCD severity and QoL aspects. Some of the predictions made by the present study were supported while some were not. The negative correlation between OCD severity and physical functioning found in the present study is contradicting with past studies (Kugler et al., 2013). Similarly, the significant mediation role of depression severity for the relationship between OCD severity and general health is unexpected (Kugler et al., 2013). The contradicting findings can be accounted for by the cross-cultural differences in the symptomology of OCD. It is possible that different expression of OCD affects QoL differently, and thus, contributed to the counterintuitive findings. We propose that the result obtained in this study is largely contributed by the effect of ethnicity. This is indicated by other OCD studies that measure among ethnic groups and suggested significant racial differences, with Southeast and South Asian students reported significantly more symptoms when compared to their African American/black, white, and Latino counterparts (Washington, Norton, \& Temple, 2008).

The relationship between OCD severity/social functioning and emotional well-being were positively mediated by depression in this population. These findings suggest that OCD severity affects emotional well-being and social functioning through depression severity, which is consistent with Kugler et al (2013)'s study. The combination of OCD and depression severity may contribute to mental health burden, and therefore, leads to a decline in emotional and social functioning. From the significant mediation models, it is also possible for OCD severity to manifest into depressive symptoms in degrading the QoL aspects. This is in line with the ongoing discussion regarding the mediating role of depressive symptoms in the relation between OCD and emotional health, social functioning and general health (Kugler et al., 2013).

Like other mental health disorders, OCD is a multifaceted and complex psychiatric disease where there are many other causes and conditions that can influence among each other. Therefore, it is important to highlight factors and limitations which can affect results of this study. First of all, the inclusion of general population limits the generalizability of the results. In addition, the sample used may not be representative of all members of public in Malaysia. Future research can consider recruiting larger and more diverse samples in terms of social status and career. Previous study showed that different dimensions of obsessive-compulsive symptoms predicted different levels of QoL in OCD patients (Fontenelle et al., 2010), which is also another limitation in the present study since there is no effort to explore for the symptoms of OCD (such as washing or hoarding). It would be interesting to study for the symptoms of OCD in the Malaysian population, which could be different from what has been documented with Western sample. While the findings suggest that OCD severity was positively related to depression severity, we could not determine the direction of their relationships. For example, it could be that participants who have depression symptoms may show OCD features, or, OCD conditions may tend to cause the patient to express the form of depressive symptoms.

\section{Acknowledgments}

This project was supported by FRGS (Fundamental Research Grant Scheme, from the Ministry of Higher Education Malaysia) and Jeffrey Cheah School of Medicine and Health Sciences, Monash University Malaysia. Well done to our research team which comprised of Soon Li Lee, Cai Lian Tam, Beng Kah Song and Tina Ting Xiang Neik. The endless support, encouragement and effort among team members were essential in making this research a success.

\section{References}

Abdul Hamid, A. R., \& Abdul Razak, O. (2010). Obsessive-compulsive disorder in schizophrenia: Clinical and neurocognitive correlates. Malaysian Journal of Psychiatry, 19(2), 1-9.

Abramowitz, J. S., Storch, E. A., Keeley, M., \& Cordell, E. (2007). Obsessive-compulsive disorder 
withcomorbid major depression: What is the role of cognitive factors? Behavior Research and Therapy, 45(10), 2257-2267. http://dx.doi.org/10.1016/j.brat.2007.04.003

American Psychiatric Association (2000). Diagnostic and Statistical Manual of Mental Disorders. APA: Washington, DC.

Besiroglu, L., Uguz, F., Saglam, M., Agargun, M. Y., \& Cilli, A. S. (2007). Factors associated with major depressive disorder occurring after the onset of obsessive-compulsive disorder. Journal of Affective Disorders, 102(1-3), 73-79. http://dx.doi.org/10.1016/j.jad.2006.12.007

Blom, R. M., Hagestein-de Brujin, C., De Graaf, R., Ten Have, M., \& Denys, D. A. (2011). Obsession in normality and psychopathology. Depression and Anxiety, 28(10), 870-875. http://dx.doi.org/10.1002/da. 208553

Cassin, S. E., Richter, M. A., Zhang, K. A., \& Rector, N. A. (2009). Quality of life in treatment-seeking patients with obsessive-compulsive disorder with and without major depressive disorder. Canadian Journal of Psychiatry, 54(7), 460-467.

Crino, R., Slade, T., \& Andrews, G. (2005). The changing prevalence and severity of obsessive-compulsive disorder criteria from DSM-III to DSM-IV. The American Journal of Psychiatry, 162(5), 876-882. http://dx.doi.org/10.1176/appi.ajp.162.5.876

Foa, E. B., Huppert, J. D., Leiberg, S., Langer, R., Kichic, R., ... \& Salkovskis, P. M. (2002). The Obsessive -Compulsive Inventory: Development and validation of a short version. Psychological Assessment, 14(4), 485-496. http://dx.doi.org/10.1037//1040-3590.14.4.485

Fontenelle, I. S., Fontenelle, L. F., Borges, M. C., Prazeres, A. M., Rangé, B. P., Mendlowicz, M. V., \& Versiani, M. (2010). Quality of life and symptom dimensions of patients with obsessive-compulsive disorder. Psychiatry Research, 179(2), 198-203. http://dx.doi.org/10.1016/j.psychres.2009.04.005

Hollander, E. (1997). Obsessive-compulsive disorder: The hidden epidemic. Journal of Clinical Psychiatry, 58(12 SUPPL.), 3-6.

Hou, S. Y., Yen, C. F., Huang, M. F., Wang, P, W., \& Yeh, Y, C. (2010). Quality of life and its correlates in patients with obsessive-compulsive disorder. Kaohsiung Journal of Medical Sciences, 26(8), 397-407. http://dx.doi.org/10.1016/S1607-551X(10)70065-6

Imran, A., Azidah, A. K., Asrenee, A. R., \& Rosediani, M. (2009). Prevalence of depression and its associated factors among elderly patients in out-patient clinic of Universiti Sains Malaysia Hospital. Medical Journal of Malaysia, 64(2), 134-139.

Koran, L. M., Mcelroy, S. L., Davidson, J. R. T., Rasmussen, S. A., Hollander, E., \& Jenike, M. A. (1996). Fluvoxamine versus clomipramine for obsessive-compulsive disorder: A double-blind comparison. Journal of Clinical Psychopharmacology, 16(2), 121-129.

Kroenke, K., Spitzer, R. L., \& Williams, J. B. W. (2001). The PHQ-9: Validity of a brief depression severity measure. Journal of General Internal Medicine, 16(9), 606-613. http://dx.doi.org/10.1046/j.1525-1497.2001. 016009606.x

Leon, A. C., Portera, L., \& Weissman, M. M. (1995). The social costs of anxiety disorders. British Journal of Psychiatry, 166(27 SUPP), 19-22.

Myers, T. A. (2011). Goodbye, listwise deletion: Presenting Hot deck imputation as an easy and effective tool for handling missing data, Communication Methods and Measures, 5(4), 297-310. http://dx.doi.org/10.1080 /1 9312458.2011.624490

Nik Jaafar, N. R., Midin, M., \& Prakash Reddy, J. (2009). Obsessive compulsive schizophrenia (OCS) revisited: A five-year case report. ASEAN Journal of Psychiatry, 10(1).

Preacher, H., \& Hayes, A. F. (2004). SPSS and SAS procedures for estimating indirect effects in simple mediation models. Behavior Research Methods, Instruments, \& Computers, 36(4), 717-731. http://dx.doi.org/10.3758/BF03206553

RAND Corporation. (n. d.). 36-Item Short Form Survey from the RAND Medical Outcomes Study. Medical Outcome Study. Retrieved from http://www.rand.org/health/surveys_tools/mos/mos_core _36item.html

Rasmussen, S. A. (1994). Obsessive compulsive spectrum disorders. Journal of Clinical Psychiatry, 55(3), 89-91. 
Sherina, M. S., Rampal, L., \& Mustaqim, A. (2004). The prevalence of depression among the elderly in Sepang, Selangor. Medical Journal of Malaysia, 59, 45-49.

Sherina, M. S., Rampal, L., Aini, M., \& Norhidayati, H. (2005). The prevalence of depression among elderly in an urban area of Selangor Malaysia. The International Medical Journal, 4(2), 57-63.

Sherina, M., Arroll, B., \& Goodyear-Smith, F. (2012). Criterion validity of the PHQ-9 (Malay version) in a primary care clinic in Malaysia, Medical Journal of Malaysia, 67(3), 309-315.

Srivastava, S., Bhatia, M. S., Thawani, R., \& Jhanjee, A. (2011). Quality of life in patients with obsessive compulsive disorder: A longitudinal study from India. Asian Journal of Psychiatry, 4, 178-182. http://dx.doi.org/10.1016/j.ajp.2011.05.008

Stein, D. J., Roberts, M., Hollander, E., Rowland, C., \& Serebro, P. (1996). Quality of life and pharmaco-econon omic aspects of obsessive-compulsive disorder: A South African survey. South African Medical Journal, 86(12 SUPPL), 1579-1585.

Storch, E. A., Lewin, A. B., Farrell, L., Aldea, M. A., Reid, J., ... Murphy, T. K. (2010). Does cognitive-behavio ral therapy response among adults with obsessive-compulsive disorder differ as a function of certain comorbidities? Journal of Anxiety Disorders, 24(6), 547-552. http://dx.doi.org/10.1016/j.janx dis.2010.03.013

Subramaniam, M., Abdin, E., Vaingankar, J. A., \& Chong, S. A. (2012). Obsessive-compulsive disorder: Prevalence, correlates, help-seeking and quality of life in a multiracial Asian population. Social Psychiatry and Psychiatry Epidemiology, 47(12), 2035-2043. http://dx.doi.org/10.1007/s00127-012-0507-8

Ware, J. E., \& Sherbourne, C. D. (1992). The MOS 36-item short form health survey (SF-36). I. Conceptual framework and item selection. Medical Care, 30(6), 473-483.

Ware, J. E., Snow, K. K., Kosinski, M., \& Gandek, B. (1993). SF-36 Health Survey Manual and Interpretation Guide. The Health Institute: New England Medical Center, Boston.

Washington, C. S., Norton, P. J., \& Temple, S. (2008). Obsessive-compulsive symptoms and obsessive-compulsive disorder: A multiracial/ethnic analysis of a student population. The Journal of Nervous and Mental Disease, 196(6), 456-461. http://dx.doi.org/10.1097/NMD.0b013e3181775a62

\section{Copyrights}

Copyright for this article is retained by the author(s), with first publication rights granted to the journal.

This is an open-access article distributed under the terms and conditions of the Creative Commons Attribution license (http://creativecommons.org/licenses/by/3.0/). 